\title{
Equações de $1^{\circ}$ grau e estratégias para sua resolução por estudantes do $7^{\circ}$ ano do ensino fundamental
}

\author{
Strategies to solve first-degree equations used by seventh grade \\ elementary students
}

\author{
Beatriz Aparecida Silva Alves - UFU \\ Fabiana Fiorezi de Marco - UFU²
}

\section{RESUMO}

$\mathrm{O}$ presente trabalho apresenta reflexões sobre a formação do conceito de equações de $1^{\circ}$ grau e as estratégias de resolução elaboradas por estudantes, sob a perspectiva da Teoria Histórico-Cultural (Vigotski, 1989; 1991; Leontiev, 1978; 1983) e da atividade de ensino (Moura, 2000; 2001; 2002). A pesquisa foi realizada com 27 estudantes do $7^{\circ}$ ano do ensino fundamental de uma escola municipal de uma cidade do interior de Uberlândia/Minas Gerais, com faixa etária entre 12 a 15 anos. Para esse artigo, temos como objetivo analisar ações e reflexões dos estudantes possibilitadas pelas situações desencadeadoras que lhes foram apresentadas no processo de formação do conceito de equações de $1^{\circ}$ grau e suas resoluções. Pelas análises, podemos inferir que conseguimos gerar a necessidade nos estudantes para que se envolvessem na proposta perfazendo um ambiente de construção do conhecimento teórico, propiciando a ruptura do pensamento mecânico. Além disso, foi possível perceber que esses estudantes foram envolvidos em um processo de ensino e de aprendizagem intencionalmente organizado, compreendendo as justificativas de suas ações mediante as necessidades que os mobilizaram.

Palavras-chave: Atividade de ensino. Equação de $1^{\circ}$ grau. Teoria históricocultural.

\begin{abstract}
The present work presents reflections on the formation of the concept of first degree equations and resolution strategies drawn up by students, from the perspective of HistoricalCultural Theory (Vigotski, 1989; 1991; Leontiev, 1978; 1983), and the teaching activity (Moura, 2000; 2001; 2002). The study was conducted with 27 students of the 7 th grade of elementary school from a public school of the city of / MG (Brazil), aged between 12 and 15 years old. For this article, arguing the actions and reflections of students made possible by being situations that have been submitted in the process on formation of the concept of first degree equations. For analysis, we can infer that we can generate the need for students to engage in the proposal for a construction environment of theoretical knowledge, resulting in the rupture of mechanical thinking. Besides that, it was possible to notice that students were involved in a teaching and learning process intentionally organized, comprising the justification of their actions upon the needs that the mobilized.
\end{abstract}

Keywords: Teaching activity. First degree equations. Historical-cultural theory.

\footnotetext{
${ }^{1}$ Mestre em Ensino de Ciências e Matemática pela Universidade Federal de Uberlândia. Docente da Educação Básica na cidade de Uberlândia/MG. E-mail: beatriz.famat@gmail.com.

2 Pós Doutora em Educação pela USP/SP e Doutora em Educação Matemática pela UNICAMP. Coordenadora do GEPEMAPe - Grupo de Estudos e Pesquisa em Ensino de Matemática e Atividade Pedagógica. Professora dos Programas de Pós-Graduação em Educação e, em Ensino de Ciências e Matemática da Universidade Federal de Uberlândia. E-mail: fabiana.marco@ufu.br.
} 


\section{Introdução}

Este artigo apresenta reflexões acerca das ações dos estudantes em uma atividade de ensino (MOURA, 2000) que compõe nossa pesquisa de mestrado, desenvolvida no Programa de Pós-Graduação em Ensino de Ciências e Matemática da Universidade Federal de Uberlândia.

Nosso objeto nesse artigo versa sobre equações de $1^{\circ}$ grau e resoluções, tendo como objetivo analisar ações e reflexões dos estudantes possibilitadas pelas situações desencadeadoras que lhes foram apresentadas, no processo de formação do conceito de equações de $1^{0}$ grau e suas resoluções. Nossa intenção foi de corroborar para que os estudantes se apropriassem desse conceito e não apenas assumissem o papel de usuários que operam com letras sem atribuir nenhum tipo de significado a elas. Diante desse objetivo, nesse artigo pretendemos investigar quais implicações pedagógicas para o processo e formação do conceito de equações de $1^{\circ}$ grau para os estudantes do $7^{\circ}$ ano as atividades de ensino podem propiciar?

Diante de uma de nossas inquietudes - pensar a complexidade do nosso objeto principal, a atividade pedagógica - nos colocamos em movimento de pensar em como organizar o ensino de forma a mobilizar os estudantes à formação do conceito de equações de $1^{\circ}$ grau e suas resoluções de forma que os permitissem se apropriarem do conhecimento teórico.

Compreendemos a atividade pedagógica com objetivos e ações intencionalmente definidas (MOURA, 2000), possibilitando desencadear no estudante a necessidade da apropriação do conhecimento algébrico, mobilizando-o a apreender os conceitos historicamente produzidos. Tal movimento propicia-nos atribuir nova qualidade à nossa atividade (o ensino) e ao movimento vivido em sala de aula.

As atividades de ensino, aqui apresentadas, foram desenvolvidas com 27 estudantes do $7^{\circ}$ ano do ensino fundamental, com faixa etária entre 12 e 15 anos, de uma escola pública de uma cidade do interior de Minas Gerais.

Para este texto, fazemos uma breve apresentação acerca de como são encontradas as discussões sobre equações na literatura, nosso entendimento sobre conceito, atividade e atividade de ensino na perspectiva da Teoria 
Histórico-Cultural. Apresentamos, também, uma situação desencadeadora e seus desdobramentos.

\section{0 movimento das equações: a busca na literatura}

Sabemos que as equações podem ser consideradas como uma representação simbólica de situações vivenciadas por diferentes civilizações, a exemplificar,

Os matemáticos alexandrinos viram-se obrigados a preocuparemse com a arte do cálculo pelos problemas que encontravam na astronomia e mecânica; os Hindus devotaram uma enorme atenção aos problemas numerais de ordem comercial; os egípcios dedicaram-se aos problemas de medição de terras. (CEDRO, 2004, p. 72).

Garbi (2009) define equações algébricas como aquelas em que a incógnita aparece apenas submetida às chamadas operações algébricas: adição, subtração, multiplicação, divisão, potenciação inteira e radiciação. Para o autor, são exemplos de equações algébricas: $\mathrm{x}+4=13$, $\mathrm{a} x^{2}+\mathrm{bx}+\mathrm{c}=0, \mathrm{my}^{5}-\sqrt{3} \mathrm{y}=4$, entre outras.

Uma equação algébrica poderá assumir a qualidade de Equação Polinomial, quando estiver sob a forma canônica, isto é, $\mathrm{a}_{0} x^{n}+\mathrm{a}_{1} x^{n-1}+\cdots+\mathrm{a}_{n-2} x^{2}+$ $\mathrm{a}_{n-1} x+\mathrm{a}_{n}=0$ ( $n$ inteiro e positivo), o maior expoente da incógnita é denominado o grau da equação.

Neste estudo, nosso objeto versa sobre equações algébricas lineares com uma variável, o que nos leva a recorrer a Cedro (2004, p. 74) que as define como aquelas nas quais as variáveis (as incógnitas) são monômios de primeiro grau. Uma definição mais formal seria a seguinte: toda equação que possa ser expressa pela forma ${ }^{a_{1} x_{1}}=b$, em que ${ }^{x_{1}}$ é a incógnita e ${ }^{a_{1}}$ é um número, será chamada de equação linear com uma variável.

Buscando indícios de resolução de equações lineares ao longo do percurso histórico, encontramos que os primeiros registros foram encontrados cerca de 2000 a 1700 a.C. em tábulas de argila babilônicas e no papiro de Rhind. Para tanto, os egípcios utilizaram a ideia de Número Falso, ou método da Falsa 
Posição. Conforme proposto por Lima, Takazaki e Moisés (1998, p. 16), temos como exemplo:

Um montão e sua metade juntos somam 9. Qual é a quantidade? $1^{\circ}$ Passo: Inicialmente eles passavam a sentença para a linguagem matemática.

Um número acrescido de sua metade é igual a 9.

Campo de variação: Reais.

$2^{\circ}$ Passo: Depois eles atribuíam ao número desconhecido, à incógnita, um valor específico, particular, provavelmente falso, que nos daria um momento particular diferente do que procuramos, isto é um resultado também falso. Esse resultado era comparado com o resultado que se pretende e, usando-se proporções chega-se à resposta correta.

Por exemplo, atribuíam a incógnita o "valor falso" 20, e faziam os cálculos:

um número: 20

sua metade: $10+$

soma: $\quad 30$

A partir disto, usavam uma proporção para determinar o valor verdadeiro

valor falso $20 \quad$ um número (valor verdadeiro)

resultado falso $30 \quad 9$

Resolvendo essa proporção:

$$
\begin{aligned}
& 20=\text { um número } \\
& 30 \quad 9 \\
& \text { um número }=20.9 \\
& 30 \\
& \text { um número }=6
\end{aligned}
$$

Assim a resposta é 6 .

Já para os gregos, no período de 500 a 200 a.C., a álgebra era geométrica, "devido à sua dificuldade lógica com números irracionais e mesmo fracionários e suas dificuldades práticas com os numerais gregos" (BAUMGART,1992, p. 68). Um exemplo, apresentado por Lima, Takazaki e Moisés (1998, p. 18-19) é: O dobro de um número acrescido de 7 é igual a 25.

Inicialmente traçava-se uma medida igual ao resultado da equação:

Escrevia-se a sentença matemática dada:

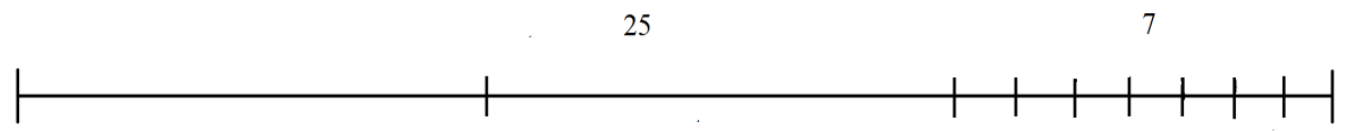


Então, efetuavam-se os cálculos: $25-7=18$ e, $18 \div 2=9$

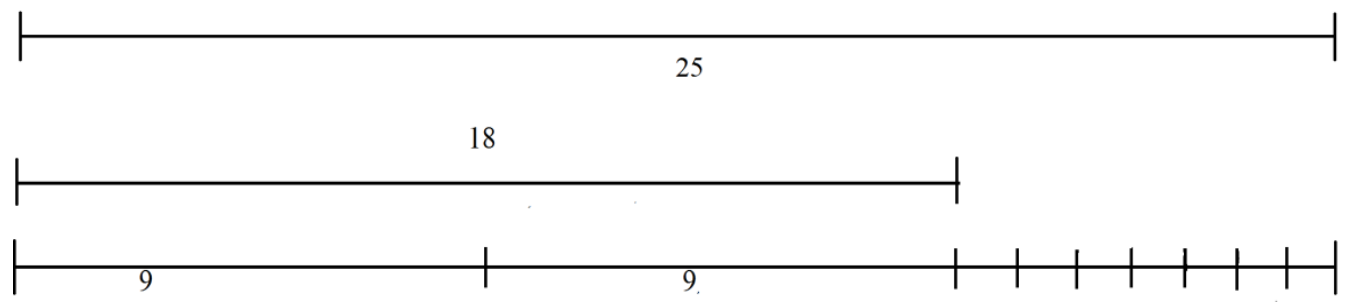

Assim, o número é 9.

Neste estudo, compreendemos o conceito de equação conforme as palavras de Lima, Takazaki e Moisés (1998, p. 13), ou seja, "equação matemática é a sentença matemática referente a um problema algébrico particular, isto é, é toda sentença matemática que contêm variáveis e é expressa por um sinal de igualdade".

Ao consideramos o ensino desta na educação básica, notamos a importância deste movimento se fazer presente na construção do conhecimento teórico dos estudantes, pois, ao longo do processo de formação da linguagem algébrica simbólica, a álgebra contém o movimento da vida a partir dos movimentos presentes nos problemas da vida das diversas civilizações, um movimento não linear, pautado na mutabilidade e fluência do pensar humano "presente nos estágios denominados de retórico, sincopado e geométrico - que leva ao pensamento flexível da realidade, elaborado pelas várias civilizações, nos diversos momentos históricos” (LANNER DE MOURA; SOUSA, 2005, p. 12).

Diante do exposto, buscamos apresentar brevemente alguns movimentos que constituíram a álgebra simbólica da forma como a conhecemos hoje, bem como, alguns métodos para resolvermos equações algébricas lineares, ou as equações de $1^{\circ}$ grau.

\section{A formação dos conceitos sob a perspectiva de Vigotski}

Vigotski (1989) considera dois tipos de conceitos: espontâneos (adquiridos fora do contexto escolar) e científicos (sistematização de ideias interrelacionadas). Podemos pensar nos conceitos espontâneos (cotidianos) como os 
conhecimentos prévios que o estudante possui e que o ajudam a interpretar algo melhor; estes evoluem na medida em que há aprendizagem, podendo ser generalizados, partindo do concreto para o abstrato. Já os conceitos científicos instigam o estudante, dizem respeito às relações das palavras com outras palavras, sua sistematização, partindo do abstrato para o concreto. Assim, Vigotski (1989) apresenta a ideia de que a educação promove o desenvolvimento cognitivo, onde o desenvolvimento dos conceitos espontâneos e científicos está em constante consonância.

Poder-se-ia dizer que o desenvolvimento dos conceitos espontâneos da criança é ascendente, enquanto o desenvolvimento dos seus conceitos científicos é descendente, para um nível mais elementar e concreto. [...] Ao forçar sua lenta trajetória para cima, um conceito cotidiano abre o caminho para um conceito científico e o seu desenvolvimento descendente. Cria uma série de estruturas necessárias para a evolução dos aspectos mais primitivos e elementares de um conceito, que lhe dão corpo e vitalidade. Os conceitos científicos, por sua vez, fornecem estruturas para o desenvolvimento ascendente dos conceitos espontâneos da criança em relação à consciência e ao uso deliberado. Os conceitos científicos desenvolvem-se para baixo por meio dos conceitos espontâneos; os conceitos espontâneos desenvolvem-se para cima por meio dos conceitos científicos. (VYGOTSKY, 1989, p. 93-94).

Sendo assim, a aprendizagem como atividade transformadora utiliza-se de ferramentas mediadoras (instrumentos e signos) para agir sobre o objeto.

Vigotski considera os instrumentos e os signos como os principais elementos mediadores da atividade:

A função do instrumento é servir como condutor da influência humana sobre o objeto da atividade; ele é orientado externamente; deve necessariamente levar a mudanças nos objetos. Constitui um meio pelo qual a atividade humana externa é dirigida para o controle e domínio da natureza. O signo, por outro lado, não modifica em nada o objeto da operação psicológica. Constitui um meio da atividade interna dirigido para o controle do próprio indivíduo; o signo é orientado internamente. (VYGOTSKY, 1991, p. 41).

A linguagem assume o papel na comunicação entre os indivíduos e por meio dela se podem estabelecer os significados. Concordamos com as ideias de Vigotski (1991) quando alega que 
a capacitação especificamente humana para a linguagem habilita as crianças a providenciarem instrumentos auxiliares na solução de tarefas difíceis, a superar a ação impulsiva, a planejar uma solução para um problema antes de sua execução e a controlar seu próprio comportamento. Signos e palavras constituem para a criança, primeiro e acima de tudo, um meio de contato social com outras pessoas. As funções cognitivas e comunicativas da linguagem tornam-se, então, a base de uma forma nova e superior de atividade nas crianças distinguindo-as dos animais. (VYGOTSKY, 1991, p. 24).

Entendemos que a palavra atua como mediadora, constituindo as relações e generalizações construídas pelo indivíduo no social em um determinado período histórico, podendo ser entendida como um signo, inicialmente como papel na formação do conceito e, posteriormente, atua como o seu símbolo.

\section{$4 \mathrm{O}$ conceito de atividade}

Para Leontiev (1983, p.15), "a atividade em sua forma inicial e principal é a atividade prática sensitiva mediante a qual as pessoas entram em contato prático com os objetos do mundo que as circundam, experimentam sua resistência, influem sobre eles, subordinando-se à suas propriedades objetivas”.

Esse mesmo autor, em outra obra, define atividade como "os processos psicologicamente caracterizados por aquilo a que o processo, como um todo, se dirige (seu objeto), coincidindo sempre com o objetivo que estimula o sujeito a executar esta atividade, isto é, o motivo" (LEONTIEV, 1978, p. 68).

Uma situação pode ser caracterizada como atividade mediante os seguintes elementos: objeto, motivo, operação/ação e objetivo, sendo que o objeto e o motivo devem sempre coincidir dentro de uma atividade, "o objeto da atividade é seu motivo real" (LEONTIEV, 1983, p. 83). Esse motivo pode tanto ser externo como ideal, percebidos ambos como existentes somente na imaginação, na ideia. $\mathrm{O}$ conceito da atividade está necessariamente relacionado ao conceito de motivo, a atividade somente existe mediante o objetivo, pois "podemos dizer que um sujeito se encontra em atividade quando o objetivo de sua ação coincide com o motivo de sua atividade, e esta deverá satisfazer uma necessidade do indivíduo e do grupo 
em sua relação com o mundo, procurando atingir um objetivo" (MARCO, 2009, p. 28).

Para apropriar-se dos objetos ou dos fenômenos, produtos do desenvolvimento histórico, Leontiev (1978, p.268) propõe a aquisição de instrumentos, "produto da cultura material que leva em si, da maneira mais evidente e mais material, os traços característicos da criação humana”. O instrumento torna-se então um objeto social, onde são incorporadas operações de trabalho historicamente elaboradas, o que nos leva a inferir que o instrumento é o meio que permite ao homem transformar o objeto da atividade.

Dando continuidade ao conceito de atividade e tendo em vista a necessidade de pensarmos em instrumentos para a organização de nossa atividade pedagógica, apresentamos a seguir o olhar de Moura (2000; 2001; 2002), acerca na atividade no contexto escolar.

Os estudos de Moura $(2000 ; 2001 ; 2002)$ nos remetem à necessidade da organização do ensino de forma intencional, uma vez que compreendemos a escola "como lugar social privilegiado para a apropriação de conhecimentos produzidos historicamente" (MOURA et al., 2010, p. 89).

Incorporando ao conceito de atividade, Moura (2000) volta seu olhar para o ensino e defende que a atividade de ensino tem como objetivo "organizar uma sequência de conteúdos escolares que permitem cumprir com determinado objetivo educacional" (MOURA, 2000, p. 22). Mais ainda, define atividade orientadora de ensino (AOE), como

aquela que se estrutura de modo a permitir que sujeitos interajam, mediados por um conteúdo, negociando significados, com o objetivo de solucionar coletivamente uma situação-problema. É atividade orientadora porque define elementos essenciais da ação educativa e respeita a dinâmica das interações que nem sempre chegam a resultados esperados pelo professor. Este estabelece os objetivos, define as ações e elege os instrumentos auxiliares de ensino, porém não detém todo o processo, justamente porque aceita que os sujeitos em interação partilhem significados que se modificam diante do objeto de conhecimento em discussão. (MOURA, 2002, p. 155).

Entendemos assim, que a AOE é concebida como uma unidade formadora, entre as atividades de ensino e as de aprendizagem, na qual 
a Atividade Orientadora de Ensino tem uma necessidade: ensinar; tem ações: define o modo ou procedimentos de como colocar os conhecimentos em jogo no espaço educativo; elege instrumentos auxiliares no ensino: os recursos metodológicos adequados a cada objetivo e ação (livro, giz, computador, ábaco, etc.). E por fim, os processos de análise e síntese, ao longo da atividade, são momentos de avaliação permanente para quem ensina e aprende. (MOURA, 2001, p. 155).

O professor, ao se colocar em atividade de ensino, continua apropriando-se de conhecimentos teóricos, organizando suas ações, pois "a atividade de ensino quase sempre está associada à ideia de busca do professor por um modo de fazer com que o estudante aprenda um determinado conteúdo escolar" (MOURA, 2000, p. 23), fomentando a atividade de aprendizagem, atividade essa a qual pode permitir a apropriação dos conhecimentos teóricos.

Frente ao exposto, nesse estudo, buscamos compreender o movimento de atividade de aprendizagem realizado pelos estudantes, nos remetendo às suas ações e reflexões possibilitadas pelas atividades de ensino que lhes foram apresentadas no processo de formação do conceito de equações de $1^{\circ}$ grau.

Para tanto, buscamos Moura (2001) para entendermos que a natureza do conhecimento que o professor pretende ensinar indica uma perspectiva para se relacionar com os estudantes, um direcionamento para organizar o espaço de aprendizagem e o direcionamento para escolha dos instrumentos que possibilitarão uma melhor apreensão do conteúdo por parte dos estudantes.

Desta forma, assim como o referido autor, entendemos por conteúdos matemáticos "aqueles que permaneceram como patrimônio cultural, porque de algum modo, contribuem para a solução de problemas ainda relevantes para o convívio social” (MOURA, 2001, p.148), adquirindo assim objetivo social aliado à história da humanidade para resolver problemas.

Vemo-nos, então, diante da necessidade de compreender melhor como o conteúdo matemático de álgebra fora produzido historicamente e as concepções existentes, a fim de melhor dimensioná-lo no contexto escolar.

Dentre as pesquisas consultadas, temos Sousa (2004) que considera os nexos conceituais da álgebra (fluência, variável, campo de variação) como 
elementos necessários para uma melhor compreensão dos conceitos algébricos e, possivelmente, das equações. A autora alega que

os nexos conceituais que fundamentam os conceitos contêm a lógica, a história, as abstrações, as formalizações do pensar humano no processo de constituir-se humano pelo conhecimento.

Definimos nexo conceitual como o elo de ligação entre as formas de pensar o conceito, que não coincidem, necessariamente, com as diferentes linguagens do conceito. (SOUSA, 2004, p. 61-62).

Podemos inferir que os nexos conceituais se apresentam no movimento do pensamento, tanto do professor, quanto do estudante. Os nexos conceituais (fluência, campo de variação e variável) são considerados na elaboração de nossa proposta, uma vez que estes consideram o movimento do surgimento da álgebra e possibilitam que o estudante se aproprie do pensamento algébrico e do conceito de equações de $1^{\circ}$ grau. Nas palavras de Sousa, Panossian e Cedro (2014, p. 121):

Esses conceitos, aos quais estamos denominando de nexos conceituais da álgebra, constituem o substancial, o movimento do pensamento algébrico, tendo em vista a busca da verdade relativizada. Fundamentam as diversas álgebras, elaboradas estruturalmente pelos matemáticos das diversas civilizações, de tempos em tempos, no intuito de descrever, de formalizar os diversos movimentos presentes no mundo no qual estamos inseridos.

Ao direcionarmos nosso olhar à fluência dos fenômenos e objetos presentes em nossa realidade, possibilitamo-nos compreender as inúmeras relações e constantes transformações desta realidade.

O mundo está em permanente evolução; todas as coisas, a todo momento, se transformam, tudo flue, tudo devém. Isto, que é a afirmação fundamental do filósofo Heráclito de Efeso foi, posteriormente, reconhecido por grandes pensadores e pode ser verificado por qualquer de nós, seja qual for aquele objecto em que fixemos a nossa atenção. Pois não é verdade que tudo está sujeito a uma mesma lei de nascimento, vida e morte, que, por sua vez, vai originar outros nascimentos? (CARAÇA, 1951, p. 110).

Esse primeiro nexo conceitual parece evidenciar o movimento da vida, a mutabilidade da álgebra, mostrar aos estudantes os caminhos percorridos para se chegar à configuração que temos hoje, se relacionando com os nexos conceituais campo de variação e variável. 
Sobre o campo de variação, Panossian (2014) remete à criação de diversos campos numéricos, ou campo de variação, como uma necessidade das diferentes civilizações, possibilitando a garantia de fluência do movimento de controle de quantidades, pois

consideramos que a qualidade desses campos numéricos se alterava em um movimento de evolução, no sentido em que sua essência não se modificava, mas se modificavam outras qualidades. É o que acontece, por exemplo, com a necessidade da criação de números que podem ser representados na forma de razão, os quais avançam de forma gradativa modificando a qualidade do número. Ou ainda com a organização de um campo de números inteiros, em que a quantidade negativa adquire significado. (PANOSSIAN, 2014, p. 91).

Notamos que o campo de variação define dentro de um conjunto numérico, as possibilidades de valores que a variável poderá assumir. Esse campo estará associado ao tipo de problema a ser estudado e depende "diretamente do movimento da realidade tratada. Não há uma resposta pronta e absoluta, embora boa parte dos movimentos da realidade pareça ocorrer no campo dos números reais" (SOUSA, 2004, p. 158).

Em relação à variável e diante das ideias de Caraça (1951) podemos inferir que a variável é a fluência e representa o movimento do pensamento.

Pelo seu caráter essencial - síntese do ser e não ser - ela sai fora daquele quadro de ideias que quer ver na realidade uma permanência e irrompe ligada à corrente de pensamento que, expressa ou tacitamente, vê na fluência a primeira de suas características. (CARAÇA, 1951, p. 127, grifos do original).

Entendemos que a constituição da variável leva em consideração as dimensões numéricas e geométricas, "o seu lógico-histórico mostra que estes se originaram das abstrações feitas pelos homens a partir da elaboração dos conceitos formais de número e de aspectos da geometria” (SOUSA, 2004, p. 82).

Conforme Caraça (1951, p. 128), "variável é o que for determinado pelo conjunto numérico que ela representa - a sua substância, o seu domínio", assim a variável estará dentro do movimento limitado por um campo de variação. Esse mesmo autor ainda define variável da seguinte forma: "Seja (E) um conjunto qualquer de números, conjunto finito ou infinito, e convencionamos representar 
qualquer dos seus elementos por um símbolo, por ex.: $x$. A este símbolo, representativo de qualquer dos elementos do conjunto (E), chamamos de variável” (CARAÇA, 1951, p. 127).

Lima, Takazaki e Moisés (1998) esclarecem que o problema algébrico geral, caracteriza o movimento geral de variação quantitativa e o problema algébrico particular buscará na variável um valor definido, dentro do campo de variação, que satisfaça uma determinada situação. Nesse caso, estamos nos referindo a variável na qualidade de incógnita, ou termo desconhecido, devendo este pertencer ao mesmo campo de variação, pois caso contrário, o problema não terá solução.

A variável passa a adquirir qualidade por meio da fluência, um movimento limitado pelo campo de variação, que "constitui uma linguagem para os movimentos quantitativos gerais - as equações - que, por sua vez, representam uma peculiaridade e, portanto, constituem uma linguagem particular, específica, um estado de movimentos de controle de quantidades" (CEDRO, 2004, p. 82).

Nesta mesma perspectiva, encontramos Caraça (1951) que destaca o conceito de variável como fundamento principal para toda a álgebra fundamental e, consequentemente, para sequências, equações e funções. Para o bloco sequências temos a variável relacionada à fluência e à padrão; para equações, temos a relação entre grandezas e, para funções, temos a variável relacionada à interdependência e fluência.

Assim, acreditamos que, diante da intencionalidade de apresentar uma proposta de ensino que abarque os nexos fluência, variável e campo de variação, os estudantes poderão colocar-se em atividade e apropriar-se do conceito de equações de $1^{\circ}$ grau, uma vez que esses nexos consideram o movimento histórico de formação do conceito algébrico.

\section{A proposta de ensino e alguns desdobramentos}

Ao pensarmos no caminho metodológico para direcionar nossa pesquisa, sentimos a necessidade de acompanharmos os processos pelos quais nossos 
sujeitos perpassaram e não somente o produto final de suas ações. Este fato nos direcionou a buscar no materialismo de Marx e no método de Vigotski um caminho para organizarmos nossa pesquisa.

Agregar ao nosso estudo o materialismo histórico dialético se justifica por termos um direcionamento para investigar as mais simples manifestações dos sujeitos da pesquisa e, ao nos debruçarmos sobre estas, elaborando abstrações, poderemos compreender o movimento de apropriação de conhecimento dos estudantes envolvidos neste estudo.

Para Vigotski (2001) estudar algo historicamente é sinônimo de estudar o fenômeno em movimento, momento esse de suma importância ao método, pois

quando numa investigação se abarca o processo de desenvolvimento de algum fenômeno em todas as suas fases e mudanças, desde que surge até que desapareça, isso implica manifestar sua natureza, conhecer sua essência, já que somente em movimento demonstra o corpo que existe. Assim, pois, a investigação histórica da conduta não é algo que complementa ou ajuda o estudo teórico, mas consiste seu fundamento. (VYGOTSKY, 2001, p. 67-68).

O materialismo histórico dialético de Marx influenciou o desenvolvimento do método de investigação da psicologia histórico-cultural de Vigotski. Cole e Scribner (1998) apresenta três princípios no método de investigação que o diferencia dos métodos utilizados em outras abordagens teóricas: 1) análise de processos, em substituição à análise de objetos; 2) explicação do fenômeno em substituição à descrição do mesmo; 3) investigação do "comportamento fossilizado".

Assim, ao tomarmos a sala de aula como nosso campo de investigação, como um "ambiente natural" da formação do conhecimento teórico de estudantes, acreditamos nos aproximar das características de uma pesquisa de enfoque qualitativo.

Para o desenvolvimento da proposta utilizamos a dinâmica indivíduogrupo-classe (LANNER DE MOURA et al., 2003) objetivando o compartilhamento de sentimentos, experiências, significados e conhecimentos. Nessa dinâmica, num primeiro momento, o indivíduo está no movimento do pensar individual sobre a situação-problema encontrada e atribuir significados a ela; posteriormente, em 
pequenos grupos, poderá apresentar suas ideias a fim de que o grupo elabore uma síntese coletiva que o represente e, por fim, termos a discussão grupo-classe para encontrar uma possível solução ou a mais adequada para todo o grupo-classe - e que ocorre orientada pelo professor.

Para tanto, apresentávamos à classe problemas e solicitávamos que eles criassem uma equação para o problema enunciado. Os estudantes eram convidados a pensarem sozinhos inicialmente, em seguida, poderiam discutir com seus pares e, após alguns minutos, socializar para a classe a solução pelo pequeno grupo. Alguns estudantes formavam duplas, outros trios, sendo que tais formações ocorreram por afinidade entre os mesmos, sem qualquer interferência da professora. Posteriormente, eram convidados, na dinâmica indivíduo-grupoclasse, elaborarem estratégias de resolução para as equações formuladas.

Como instrumentos de produção e construção do material analisado utilizamos: a) registro, individual e em grupo, das atividades desenvolvidas pelos estudantes; b) registros no diário de campo da professora pesquisadora; c) áudio das discussões ocorridas entre os estudantes durante o caminhar e a produção das atividades; d) registro visual (fotos) das ações dos estudantes no decorrer das atividades.

Os registros audiovisuais e escritos permitiram o olhar acurado, o distanciamento da professora para então tornar-se apenas pesquisadora, visando a busca de aspectos relevantes à pesquisa, uma vez que, enquanto inseridas no movimento de sala de aula, muitas são as inquietudes dos estudantes no decorrer do processo e, poderíamos deixar escapar detalhes importantes. Assim, os registros audiovisuais permitiram a retomada desse processo com o foco nas ações e discussões dos estudantes.

Como critérios para a seleção dos sujeitos da pesquisa tivemos: a) frequência constante nas aulas; b) ter apresentado suas reflexões nos registros escritos e socialização na turma; c) ter vivenciado as atividades propostas, ou seja, ter participado da maior parte do movimento da proposta de atividades de ensino. Diante disso, nossos sujeitos, como já mencionado, foram estudantes de uma escola pública do interior de uma cidade de Minas Gerais, situada na zona rural da cidade. Tal denominação deve-se ao fato de a escola receber estudantes 
que residem em chácaras, não havendo loteamento e infraestrutura presente nos bairros urbanos. A comunidade é composta por famílias que ali residem buscando um local para constituírem seus lares onde, por serem afastados do perímetro urbano, os lotes podem ser adquiridos por um valor monetário mais acessível. As famílias, em sua maioria, são formadas por produtores rurais, mas que produzem apenas para o próprio consumo, muitos dos pais são chefes de família que antes do amanhecer do dia deixam suas casas rumo à "cidade", como eles mesmos se referem, para mais um dia de trabalho e retornam apenas ao anoitecer para seus lares. As atividades de ensino que se seguem foram organizadas pela professora pesquisadora e serão apresentadas com seus objetivos, duração para seu desenvolvimento, nexos conceituais, na ordem cronológica em que foram propostas aos estudantes durante a pesquisa. Tínhamos como objetivos nessas atividades de ensino gerar a necessidade em nossos estudantes para que essas se constituíssem em atividade de aprendizagem, na perspectiva da atividade orientadora de ensino (MOURA, 2000).

Para analisarmos o material produzido no desenvolvimento da proposta, como aporte metodológico, utilizamos a ideia de episódios (MOURA, 2004), que propõe a escolha de alguns momentos que explicitem ações reveladoras do processo de formação dos sujeitos participantes. Nas palavras do autor,

Os episódios poderão ser frases escritas ou faladas, gestos e ações que constituem cenas que podem revelar interdependência entre os elementos de uma ação formadora. Assim, os episódios não são definidos a partir de um conjunto de ações lineares. Pode ser uma afirmação de um participante de uma atividade não tendo impacto imediato sobre os outros sujeitos da coletividade. Esse impacto poderá estar revelado em um outro momento em que o sujeito foi solicitado a utilizar-se de algum conhecimento para participar de uma ação no coletivo .(MOURA, 2004, p. 276).

Para nossas análises na pesquisa, organizamos nosso material em dois eixos: situações desencadeadoras de aprendizagem e ações e reflexões coletivas, onde cada eixo é composto por episódios e cenas (MOURA, 2004) formadas por diferentes trechos isolados do desenvolvimento da proposta desenvolvida, conforme apresentamos no quadro a seguir: 
Quadro 1 - Eixos de Análise elaborados para a pesquisa.

\begin{tabular}{|c|c|c|}
\hline Eixos de Análise & Episódios & Cenas \\
\hline \multirow{3}{*}{$\begin{array}{c}\text { Situações } \\
\text { Desencadeadoras } \\
\text { de Aprendizagem }\end{array}$} & História Virtual do Conceito & O Arquiteto Amon Toado \\
\hline & \multirow{2}{*}{ Jogos } & Banco Imobiliário \\
\hline & & Quiz \\
\hline \multirow{5}{*}{$\begin{array}{c}\text { Ações e Reflexões } \\
\text { Coletivas }\end{array}$} & \multirow{3}{*}{$\begin{array}{c}\text { Apropriação dos Nexos } \\
\text { Conceituais }\end{array}$} & Fluência \\
\hline & & Variável \\
\hline & & Campo de Variação \\
\hline & \multirow{2}{*}{$\begin{array}{l}\text { Formação do Conceito de } \\
\text { Equação de } 1^{\circ} \mathrm{Grau}\end{array}$} & $\begin{array}{l}\text { Equacionamento de } \\
\text { Problemas }\end{array}$ \\
\hline & & Estratégias de Resolução \\
\hline
\end{tabular}

Fonte: Sistematização das Autoras (2014).

Nosso olhar se voltou às ações e reflexões coletivas desenvolvidas pelos estudantes, pois acreditamos no desenvolvimento do pensamento do sujeito por meio das interações coletivas (VYGOTSKY, 1989), permitindo-lhes compartilhar conhecimentos e modificar suas ações. Destarte, elencamos duas cenas de um episódio para nossa análise neste artigo:

Quadro 2 - Eixo de Análise retratados nesse artigo

\begin{tabular}{|c|c|c|}
\hline Eixo de análise & Episódio & Cenas \\
\hline $\begin{array}{c}\text { Ações e Reflexões } \\
\text { Coletivas }\end{array}$ & $\begin{array}{c}\text { Formação do Conceito de } \\
\text { Equação de } 1^{\circ} \mathrm{Grau}\end{array}$ & Equacionando um Problema \\
\cline { 3 - 3 } & Estratégias de Resolução \\
\hline
\end{tabular}

Fonte: Sistematização das Autoras (2014).

Cena 1: Equacionando um problema

Após a realização de algumas propostas, os estudantes conseguiram formular sua própria definição para equação de $1^{\circ}$ grau e, então, almejávamos que conseguissem equacionar problemas, fazendo uso da linguagem simbólica.

Para tanto, apresentávamos à classe problemas e lançávamos como desafio que eles criassem uma equação para resolvê-los. Os estudantes eram convidados 
a pensarem sozinhos inicialmente, em seguida, poderiam discutir com seus pares e, após alguns minutos, socializar para a classe a equação formulada pelo pequeno grupo. Alguns estudantes formavam duplas, outros trios ou quartetos, sendo que tais formações ocorriam por afinidades, sem qualquer interferência da professora.

A cena, que ora apresentamos, foi desencadeada pela seguinte proposta da professora:

Tenho agora um desafio a vocês. Gostaria que escrevessem uma equação para o seguinte problema: Ana ganhou uma caixa com bombons de sua mãe. Sua tia deu-lhe mais 12 bombons. Ana contou os bombons e descobriu que possui 25 unidades. Quantos bombons Ana tinha na caixa?

Um trio foi formado pelos estudantes Carlos, Junior e Pedro Henrique ${ }^{3}$, estabeleceu o seguinte diálogo:

Carlos: Nós queremos descobrir a quantidade de bombons.

Pedro Henrique: Eu acho que, então, esse tanto que a gente não sabe, coloca a letra, então vamos colocar p de Pedro.

Carlos: Então tá. Vai ser p para o tanto de bombons, isso é o começo do problema, aí ela ganhou 12 e ficou com 25. Como a gente vai escrever uma equação?

Carlos: Se ela ganhou então aumenta, vai ser o sinal de mais. Então fica $\mathrm{p}+12$.

Junior: Tá, 25 é o total, a equação tem que ter o igual, como 25 é o resultado, acho que ele fica depois do igual então.

Carlos: Ué então fica, $\mathrm{p}+12=25$.

Pelo diálogo do trio, percebemos que o registro da equação indica um elo de sentidos estabelecidos pelos estudantes do conceito de equação como uma sentença matemática, que contem variáveis e é expressa por um sinal de igualdade (LIMA; TAKAZAKI; MOISÉS, 1998). Esse fato nos leva a recorrer à Vigotski (2001) que entende o processo de formação de conceitos como uma síntese complexa, no qual "o momento central de toda essa operação é o uso funcional da palavra como meio de orientação arbitrária da atenção, da

\footnotetext{
${ }^{3}$ Salientamos que esses nomes são fictícios, pois assumimos a responsabilidade de preservar a identidade de nossos protagonistas.
} 
abstração, da discriminação de atributos particulares e de sua síntese e simbolização com o auxílio do signo" (p. 236).

Além disso, ao observar e interagir com o objeto de estudo, a incógnita, podemos inferir que esses estudantes se apropriaram e passaram a se reconhecer na mesma, como por exemplo, na fala de Pedro Henrique: Eu acho que, então, esse tanto que a gente não sabe, coloca a letra, então vamos colocar p de Pedro.

A fim de verificarmos se, de fato, houve a atribuição de sentidos culminando na apropriação do conceito de equação, indagamos os estudantes:

Professora: Tenho uma pergunta para vocês: existiria outra forma de escrevermos essa equação, nos referindo ao mesmo problema?

Silêncio por alguns instantes...

Junior: Tem sim, professora! Podia ser: $25-\mathrm{p}=12$. Porque se diminuir do total de bombons, que é 25 , o que ela tinha no início, que a gente não sabe, vai ter que dar o tanto de bombons que a tia deu pra ela.

Carlos: É isso mesmo. Também concordo.

Pedro Henrique: Mas não vale colocar $\mathrm{p}-25$ ?

Junior: Não Pedro Henrique, porque 25 é o total de tudo e o tanto que ela tinha no começo é menos de 25 , então o 25 vem primeiro, senão ia dá uma resposta negativa e não pode porque é o tanto de bombons, não faz sentido falar que ela tinha bombons negativos, porque é dela, ela tem!

Pedro Henrique: Entendi, é isso mesmo. Eu não tinha pensado isso não, mas é isso mesmo.

Por meio das diferentes sentidos apresentados pelos estudantes neste diálogo, parece-nos termos mais um indício da apropriação do conceito de equação de $1^{\circ}$ grau, pois

Tal ou tal conteúdo, significado na palavra, fixa-se na linguagem. Mas para que um fenômeno possa ser significado e refletir-se na linguagem, deve ser destacado, tornar-se fato de consciência, o que, como vimos, se faz inicialmente na atividade prática dos homens, na produção. (LEONTIEV, 1978, p. 86).

Mais ainda, "a linguagem não desempenha apenas o papel de meio de comunicação entre os homens, ela é também um meio, uma forma de consciência e do pensamento humanos.” (LEONTIEV, 1978, p. 87). 
Uma vez que entendemos ter havido a apropriação do conceito de equação de $1^{\circ}$ grau pelos estudantes, podemos inferir que eles estavam em atividade (Leontiev, 1978) durante a realização das situações propostas, onde:

Figura 1 - Elementos que categorizam estudantes em atividade conforme Leontiev (1983)

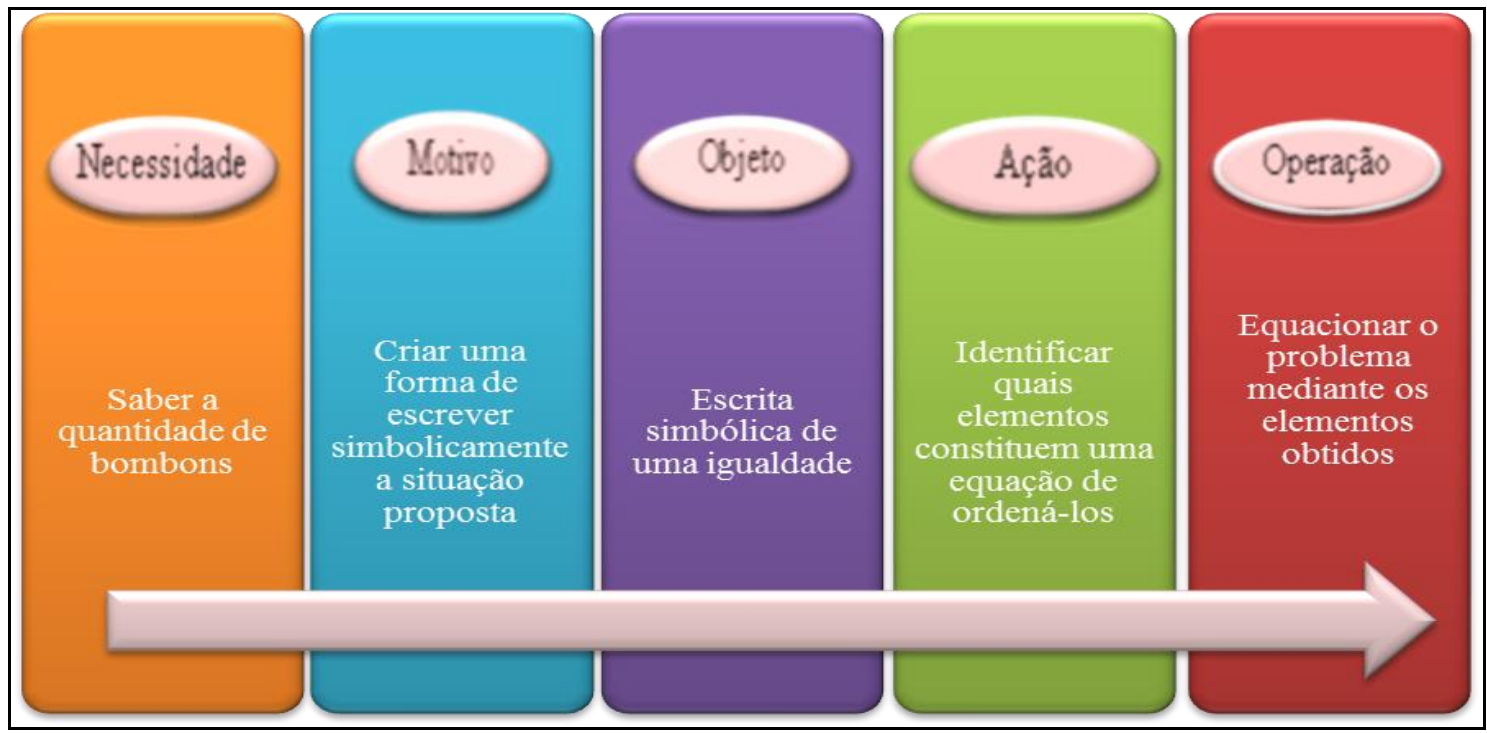

Fonte: Sistematização das Autoras (2014).

Compete aqui enfatizarmos o fato de que, em diversos momentos, os estudantes trouxeram para o diálogo os nexos conceituais da álgebra (SOUSA, 2004) que foram discutidos em outras situações durante a pesquisa. Quando o estudante Junior infere que a quantidade de bombons não poderia ser negativa, senão ia dá uma resposta negativa e não pode porque é o tanto de bombons, não faz sentido falar que ela tinha bombons negativos, porque é dela, ela tem, o mesmo remete-se ao nexo campo de variação, ao compreender o conjunto solução que se faz pertinente a essa equação.

Embora os estudantes demonstrassem apropriação do conceito e tivessem equacionado o problema proposto, ainda não haviam encontrado a solução para a questão. Acerca das estratégias de resolução das equações formuladas pelos estudantes, as apresentamos na Cena 2, onde trazemos as discussões dos estudantes em busca de uma estratégia para a resolução de equações de $1^{\circ}$ grau. 
Cena 2: Estratégias de resolução

O objetivo dessa cena perfazia nosso interesse de compreender o movimento de apropriação das estratégias de resolução da equação elaborada pelos estudantes. Sendo assim, de posse da equação que o trio Carlos, Junior e Pedro Henrique havia formulado $(p+12=25)$, nos dirigimos à lousa e instigamos a classe acerca da resolução dessa equação:

Professora: Ok classe, vocês escreveram uma equação para o problema de Ana, agora como podemos descobrir quantos bombons ela tinha?

Carlos: Professora, eu sei que a Ana tinha 13 bombons. Mas eu fiz a conta de cabeça, não usei a equação pra resolver não... eu fiz assim, com os 12 bombons que a tia deu pra ela, mais os que ela já tinha, ficam 25 bombons, então 25 menos 12 dá 13 . E se eu somar 12 mais 13 dá os 25 , então sei que minha conta tá certa.

Professora: Alguém discorda do Carlos ou pensou diferente?

Rafael: Professora, eu fiz a mesma conta, mas comecei pensando diferente do Carlos. Fiz assim, pensei que a gente precisa de um número que quando somar com 12 vai dar 25, ai eu fiz o 25 menos 12 , e deu 13.

Professora: Mas Rafael e Carlos, porque vocês fizeram 25 subtraindo 12? Os dois falaram em um número que somado ao 12 resultaria em 25 e, no entanto, fizeram uma subtração ao invés de uma adição?

Rafael: Eu pensei no problema de traz pra frente, como eu não sei o número de bombons do começo e ela ganhou bombom pra dá 25 , então se tirar os bombons que a tia deu, dá o tanto que tinha no começo. Tipo a prova real, professora, que a gente fazia no $4^{\circ}$ e $5^{\circ}$ ano.

Carlos: É professora, pensa o contrário, que dá certo!

Professora: Muito bem meninos, agora se nós tivéssemos que resolver a equação, achar essa resposta por meio dela, como poderíamos usar esse caminho que vocês encontraram para resolver a equação que foi formulada $\mathrm{p}+12=25$ ?

Fabiana: Professora, eu entendi o que os meninos falaram, então o 12 não tinha que tá antes do igual e sim depois pra ficar, $\mathrm{p}=25-12$, ai fazia a continha que eles falaram e ia achar $\mathrm{p}=13$.

Professora: Ok, Fabiana, eu acho que concordo com você, que deveríamos ter 25 menos 12 , mas combinamos que a equação seria $\mathrm{p}+12$ $=25 \ldots$ Como vamos justificar que o 12 desapareceu do primeiro membro da igualdade e apareceu do outro lado da igualdade subtraindo do 25? Rafael: Professora só se fizer assim, põe o 12 dos dois lados, aí 12 menos 12 é zero, e aparece o 25 menos 12 , depois do igual, aí vai ficar, $\mathrm{p}=25-$ 12 , como a gente queria, como a conta que eu e o Carlos fizemos.

Professora: Mas meninos e meninas, vocês concordam que eu posso fazer isso? Por que eu posso colocar o 12 subtraindo nos dois lados da igualdade? Como posso justificar esse passo?

Silêncio por alguns minutos... 
Fabiana: Professora, é o que o Rafael falou aquela hora, o caminho inverso, então tem que aparecer o 25 diminuindo 12 , e ele tem que sumir de antes do igual, o único jeito da conta dá zero pra ele sumir é tirar o mesmo tanto que tem, então tem que ser 12 dos dois lados.

Professora: Complementando a Fabiana, um pouquinho, como estamos subtraindo o 12 dos dois lados da igualdade, não estamos alterando a igualdade. Uma vez, que interferimos em ambos os lados, não a modificamos, certo?

Carlos: Certo, porque aí ele sumiu de um lado e apareceu onde a gente queria, e a senhora não muda nada, se somar o doze agora dos dois lados, volta para o que tinha antes.

Professora: Ótimo Carlos, é isso mesmo.

Figura 2- Registro do estudante Rafael
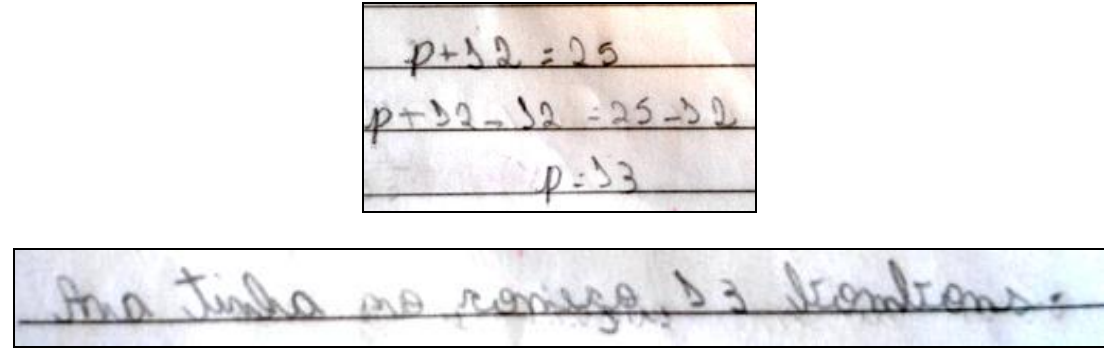

Fonte: Arquivo das Autoras.

Os estudantes, mobilizados pelo desejo de descobrir a quantidade de bombons que Ana possuía, buscaram suas próprias estratégias para resolver o problema. Coletivamente, conseguiram complementar as ideias que surgiam e justificar a estratégia utilizada. Elucidamos esse processo à luz das ideias de Moura et al. (2010) quando alegam que

(....) os sujeitos, mobilizados a partir do movimento de desenvolvimento da situação desencadeadora, interagem com os outros segundo as suas potencialidades e visam chegar a outro nível de compreensão do conceito em movimento. Além disso, o modo de ir se aproximando do conceito também vai dotando o sujeito de uma qualidade nova, ao ter que resolver problemas, pois, além de ter apreendido um conteúdo novo, também adquiriu um modo de se apropriar de conteúdos de um modo geral. (MOURA et al., 2010, p.103).

À medida que se inseriam nesse movimento e buscavam nova qualidade para a resolução da equação, os estudantes se aproximavam do método de 
resolução que fora desenvolvido por Bhaskara, conforme nos apresenta Lima, Takazaki e Moisés (1998):

De grande importância é o que ele mesmo [Bhaskara] chamou de "Método do Retorno" para resolução de equações. Método que consistia em começar a resolver as equações pelo fim. Para se chegar ao número procurado invertia-se todas as operações matemáticas que o problema prescrevia, um verdadeiro retorno sobre o enunciado. Este método encerra o princípio fundamental da álgebra em seu sentido mais puro: - 'al-jabr e wal-mugabala' restauração e redução. (LIMA; TAKAZAKI; MOISÉS, 1998, p.22).

Podemos inferir que ao relatarem sua estratégia de resolução da equação, os estudantes demonstraram ter se apropriado do Método do Retorno, como estratégia de resolução de equações de $1^{\circ}$ grau, uma vez que, por meio do coletivo, apropriaram-se de conceitos produzidos historicamente, além de atribuir nova qualidade a sua linguagem, ao fazerem uso de expressões como termos semelhantes e operações inversas, demonstrando consciência sobre o movimento desencadeado.

Pela análise do diálogo inferimos, ainda, que o desejo de resolver a situação mobilizou os estudantes para que demonstrassem a compreensão que elaboraram sobre o conceito de equação de $1^{\circ}$ grau e sua resolução, envolvendo-os no processo de formar-se.

Esse fato nos remete as ideias de Leontiev (1978), quando alega que

as aquisições do desenvolvimento histórico das aptidões humanas não são simplesmente dadas aos homens nos fenômenos objetivos da cultura material e espiritual que os encarnam, mas são aí apenas postas. Para se apropriar destes resultados, para fazer deles as suas aptidões, "os órgãos da sua individualidade", a criança, o ser humano, deve entrar em relação com os fenômenos do mundo circundante através de outros homens, isto é, num processo de comunicação com eles. Assim, a criança aprende a atividade adequada. Pela sua função, este processo é, portanto, um processo de educação. (LEONTIEV,1978, p.272).

Pelas análises realizadas, destacamos, também, a importância do desenvolvimento das relações sociais na escola, por acreditarmos que nossos estudantes apenas se envolveram com nossa proposta, por estarem inseridos em um ambiente de respeito às ideias apresentadas, não se sentindo intimidados ou constrangidos ao dialogarem com outros colegas ou com a professora. Conforme 
apresentamos nos diálogos, entendemos que a abordagem dos estudantes à professora se dava, muitas vezes, apenas para esclarecer dúvidas ou confirmar suas conjecturas, buscando assim apoio e sustentação às suas ideias.

Por tudo que foi exposto, direcionamo-nos a acreditar que os estudantes se apropriaram do conceito de equação de $1^{\circ}$ grau e da resolução das mesmas, atribuindo sentido à esse movimento, atribuindo nova qualidade a linguagem algébrica e, que compreenderam o significado no número desconhecido em uma equação.

\section{Considerações finais}

Ao final da proposta, ao discutirmos com os estudantes o ocorrido em aula, notamos uma postura crítica e autônoma, onde foram capazes de pontuar seus insucessos e motivos que levaram aos mesmos.

As análises realizadas permitiram compreender que, ao propormos situações desencadeadoras que oferecem aos estudantes a possibilidade de criar, dialogar e apreender conceitos matemáticos por meio de uma necessidade, eles conseguem atribuir sentido e apropriar-se de conceitos matemáticos historicamente produzidos (MOURA et al., 2010).

Os diálogos que apresentamos ao longo dessa análise, nos remetem a pensar a necessidade da postura do professor como mobilizador no ambiente escolar, buscando instigar seus estudantes, não apresentando respostas conclusivas as suas indagações, mas sim, promovendo questionamentos que desencadeiam soluções às perguntas de seus escolares.

A experiência de participar desta proposta, trouxe-nos algumas implicações pedagógicas:

- os estudantes tornaram-se participantes ativos no processo de aprendizagem, tendo controle e responsabilidade sobre o mesmo, uma vez que os diálogos eram motivados mediante as necessidades apresentadas por eles; 
- o planejamento das ações e os diálogos entre os estudantes ou para com a professora pesquisadora foram motivados por suas reflexões mediante o movimento da atividade de aprendizagem na qual estavam inseridos;

- a relação estudantes e situação desencadeadora fortaleceu-se e facilitou-se pelo fato dos estudantes atribuírem sentidos ao problema que tentavam solucionar, assim como pelas relações sociais que se desenvolviam;

- o reconhecimento de que a construção coletiva das soluções dos problemas propostos foi de grande importância, uma vez que passaram a valorizar a fala do outro, buscaram complementar ou afirmar os diálogos apresentados pelos estudantes ou conflitar ideias a fim de melhor elucidar o problema proposto;

- a necessidade e o motivo para aprender eram considerados na atividade, uma vez que já não mais se perguntavam para que estudar determinado conteúdo.

Conforme apresentamos nos diálogos, entendemos que a abordagem dos estudantes à professora, se dava muitas vezes apenas para esclarecer dúvidas ou confirmar suas conjecturas, buscando assim apoio e sustentação às suas ideias. Por fim, destacamos a importância do desenvolvimento das relações sociais na escola, por acreditarmos que nossos estudantes apenas se envolveram com nossa proposta, por estarem inseridos em um ambiente de respeito às ideias apresentadas, não se sentindo intimidados ou constrangidos ao dialogarem com outros colegas ou com a professora pesquisadora.

\section{Referências}

ALVES, B. A. S. A álgebra na perspectiva histórico-cultural: uma proposta de ensino para o trabalho com equações de $1^{\circ}$ grau. Dissertação (Mestrado em Ensino de Ciências e Matemática) - Faculdade de Matemática, Universidade Federal de Uberlândia, Uberlândia. 2016.

BAUMGART, J. K. Tópicos de história da matemática para uso em sala de aula: álgebra. Trad. Hygino H. Domingues. São Paulo: Atual, 1992.

CARAÇA. B. J. Conceitos fundamentais da matemática. 1 ed. Lisboa: Gradiva, 1951. 
CEDRO, W. L. O espaço de aprendizagem e a atividade de ensino: O Clube de Matemática. Dissertação (Mestrado em Educação) - Faculdade de Educação, Universidade de São Paulo, São Paulo. 2004.

COLE, M.; SCRIBNER, S. Introdução. In: COLE, M. et al. (Orgs.). A formação social da mente. Tradução de José Cipolla Neto, Luís Silveira Menna Barreto, Solange Castro Afeche. 6 ed. São Paulo: Martins Fontes, 1998.

LANNER DE MOURA, A. R. et al. Movimento conceitual: atividade de ensino e de pesquisa In: EBRAPEM - Encontro brasileiro de estudantes de pós graduação em educação matemática, 7., Rio Claro. Anais... 2003.

LANNER DE MOURA. A. R.; SOUSA, M.C. O lógico-histórico da álgebra não simbólica: dois olhares diferentes. Zetetiké - Faculdade de Educação, UNICAMP, Campinas, SP, v. 13, n.24, p.11-45, 2005.

LEONTIEV, A. N. O desenvolvimento do psiquismo. São Paulo: Editora Moraes Ltda, 1978.

. Actividad, consciência, personalidad. 2. ed. Habana: Pueblo y Educación, 1983.

LIMA, L.; TAKAZAKI, M.; MÓISES, R. P. Equações: o movimento se particulariza. São Paulo: CEVEC-CIARTE, 1998.

MARCO, F. F. Atividades computacionais de ensino na formação inicial do professor de matemática. Tese (Doutorado em Educação: Educação Matemática) - Faculdade de Educação, Universidade Estadual de Campinas, Campinas, 2009.

MOURA, M. O. O educador matemático na coletividade de formação: uma experiência com a escola pública. Tese (Livre Docência) - Faculdade de Educação, Universidade de São Paulo, São Paulo. 2000.

A Atividade de Ensino como ação formadora. In: CASTRO, A. D. de; CARVALHO, A. M. P. de (Orgs.). Ensinar a ensinar: didática para a escola fundamental e média. São Paulo: Pioneira Thompson Learning, p.143-162, 2001.

A atividade de ensino como ação formadora. In: CASTRO, A. D.; CARVALHO, Ana Maria Pessoa de (Org.). Ensinar a ensinar: didática para a escola fundamental e média. São Paulo: Pioneira Thomson Learning, 2002.

Pesquisa colaborativa: um foco na ação formadora. In: BARBOSA, R. L. L. (Org.) Trajetórias e perspectivas da formação de educadores. São Paulo: Editora UNESP, 2004, p. 257-284. 
MOURA, M. O. et al. A atividade Orientadora de Ensino como Unidade entre Ensino e Aprendizagem. In: MOURA, Manoel Oriosvaldo (Org.). A atividade pedagógica na teoria Histórico-Cultural. Brasília: Líber livro, 2010. p.81-110.

PANOSSIAN, M. L. O movimento histórico e lógico dos conceitos algébricos como princípio para constituição do objeto de ensino da álgebra. Tese (Doutorado em Educação) - Universidade de São Paulo, São Paulo, 2014.

SOUSA, M. C. O ensino de álgebra numa perspectiva lógico-histórica: um estudo das elaborações correlatas de professores do Ensino Fundamental. Tese (Doutorado em Educação Matemática) - Faculdade de Educação. UNICAMP, Campinas, 2004.

SOUSA, M. C.; PANOSSIAN, M. L.; CEDRO, W. L. Do movimento lógico e histórico à organização do ensino: o percurso dos conceitos algébricos. 1. ed. Campinas: Mercado de Letras, 2014.

VYGOTSKY, L. S. Pensamento e Linguagem. 3.ed. São Paulo: Martins Fontes, 1989.

A formação social da mente: o desenvolvimento dos processos psicológicos superiores. 4.ed. São Paulo: Martins Fontes, 1991.

Obras Escogidas III - Problemas del desarrollo de la psique. 2 ed. Madrid: Visor Dis., S.A., 2001. 